\title{
SISTEM TRANSMISI ARUS SEARAH (HVDC) MENGGUNAKAN CONVERTER 12 PULSA
}

\author{
P. Perdana Surya S. \\ Universitas Trunojoyo Madura \\ Madura, Indonesia \\ press_a@elect-eng.its.ac.id
}

\begin{abstract}
Abstrak
Abstrak- Teknologi arus searah tegangan tinggi (HVDC) mempunyai karakter menarik yang cukup bermanfaat untuk aplikasi transmisi daya listrik. Jumlah proyek HVDC berdasarkan pertimbangan secara umum telah meningkat di akhir-akhir abad ini. Paper ini menampilkan sistem kontrol transmisi HVDC menggunakan fuzzy logic controller untuk beban variabel. Simulasi dari kontrol HVDC yang diusulkan telah ditampilkan menggunakan Software Matlab. Hasil steady state dan dinamis di bawah beberapa kondisi beban telah diujikan. Hasil dari kontrol fuzzy logic controller lalu dibandingkan dengan kontrol konvensional PI. Hasilnya, kontrol sistem transmisi HVDC menggungakan Fuzzy logic controller dan PI kontroller menampilkan kelebihan dan kekurangan sendiri-sendiri dalam mengkompensasi perubahan beban.
\end{abstract}

Kata kunci: Control PI, fuzzy logic controller, Thyristor, Transmisi HVDC, Converter

\begin{abstract}
Abstract - High Voltage Direct Current (HVDC) technology has characteristics which make it especially attractive in certain transmission applications. The number of HVDC projects committed or under consideration globally has increased in recent years reflecting a renewed interest in this field proven technology. This paper presents control HVDC transmission system using fuzzy logic controller for interconnecting variable load. Simulation of the proposed HVDC control scheme has been performed using Matlab. Steady state and dynamics performance under various operating conditions have been examined. The results have been compared with conventional PI control scheme. And the result is Fuzzy logic controller and PI controllers have advantages and disadvantages to compensate dynamic konsumen load.
\end{abstract}

Keyword: Control PI, fuzzy logic controller, thyristors, HVDC Transmission, Converter 


\section{PENDAHULUAN}

Saluran listrik di dunia sebagian besar adalah saluran AC. Namun sejak perkembangan teknologi semi konduktor, khususnya teknologi thyristor, penyaluran arus searah (DC) mulai dikembangkan [1,2]. Pada tahun 1941, transmisi HVDC pertama untuk komersial disuplai dari berlin melalui kabel bawah tanah sepanjan $115 \mathrm{~km}$ dengan daya $60 \mathrm{MW}$. Pada tahun 1945 sistem ini siap untuk beroperasi. Namun, akibat perang dunia kedua, sistem ini ditinggalkan dan tidak pernah dioperasikan. Pada tahun 1954 sistem transmisi HVDC dimulai lagi dan pada umumnya diakui sebagai permulaan dari sistem transmisi DC bertegangan tinggi yang modern. Sistem ini mempunyai saluran DC dengan tegangan $100 \mathrm{kV}$ dari Vasterik di daratan Swedia ke Visby di pulau Got land, dengan jarak sepanjang $100 \mathrm{~km} \quad(62,5 \quad \mathrm{mil})$ menyeberangi Laut Baltik [3].

Sistem tegangan tinggi arus searah mempunyai beberapa kelebihan dibandingkan sistem tegangan tinggi arus bolak-balik, antara lain [3] :

1. Untuk menghubungkan sistem-sistem besar melalui jaringan-jaringan berkapasitas kecil. Sebagai contoh kita ambil Britain-France cross channel link dimana terdapat sedikit saja perbedaan frekuensi antara kedua sistem besar tersebut akan menimbulkan masalah serius bagi kontrol transfer daya pada link berkapasitas kecil. Sehingga penyaluran dengan menggunakan arus searah merupakan solusi untuk menghindari perbedaan frekuensi yang mungkin terjadi.
2. Kerugian korona pada saluran transmisi DC yang beroperasi pada suatu tegangan sama dengan harga puncak tegangan AC ekivalen jauh lebih kecil jika dibandingkan dengan transmisi tegangan tinggi AC. Hal ini penting bukan saja karena untuk mengurangi kehilangan daya yang ditimbulkan oleh peristiwa korona tersebut, tetapi juga karena interferensi yang ditimbulkan pada saluran radio maupun televisi pada umumnya.

Walaupun demikian, beberapa kerugian dalam transmisi HVDC adalah [3]:

1. Semakin banyak kondisi yang memungkinkan bagi circuit breaker untuk bekerja memutuskan rangkaian apabila arus tidak menjadi nol dalam satu siklus. Oleh karena itu switching tidak dilakukan pada link dc tetapi pada link ac Transformasi tegangan harus dilakukan pada sisi AC

2. Inverter dan Rectifier menyerap daya reaktif dan kebutuhan ini jauh lebih besar dan harus disuplai secara lokal.

3. Stasiun-stasiun konversi DC jauh lebih mahal dibandingkan dengan substation-substation AC konvesional. Hal ini karena komponen-komponen yang berfungsi untuk menyearahkan ataupun untuk membalikkan tegangan yang digunakan pada kapasitas daya besar sangat terbatas sehingga menjadi mahal.

Suatu sistem tegangan tinggi arus searah memerlukan konverter untuk mengkonversikan daya dari arus bolakbalik (AC) menjadi arus searah (DC). Thyristor dengan daya maupun tegangan yang tinggi dapat dimanfaatkan untuk peralatan konverter. 
Transmisi arus searah baru dapat dimanfaatkan dengan adanya perkembangan semikonduktor khususnya teknologi thyristor. Karena bila dengan menggunakan penyearah dioda akan menghasilkan tegangan keluaran yang tetap. Jika diinginkan suatu keluaran tegangan searah yang terkendali, maka thyristor lebih tepat digunakan dibanding dioda. Tegangan keluaran penyearah thyristor bervariasi bergantung pada sudut penyalaan pada thyristor.

Saat ini Thyristor dengan daya maupun tegangan yang tinggi dapat dimanfaatkan.untuk peralatan konvertor, yang bertujuan mengubah arus bolakbalik menjadi arus searah. Pada sisi pengiriman, arus bolak-balik dikonversi menjadi arus searah dan pada sisi terima arus searah dikonversi kembali menjadi arus bolak-balik menggunakan peralatan switching inverter.

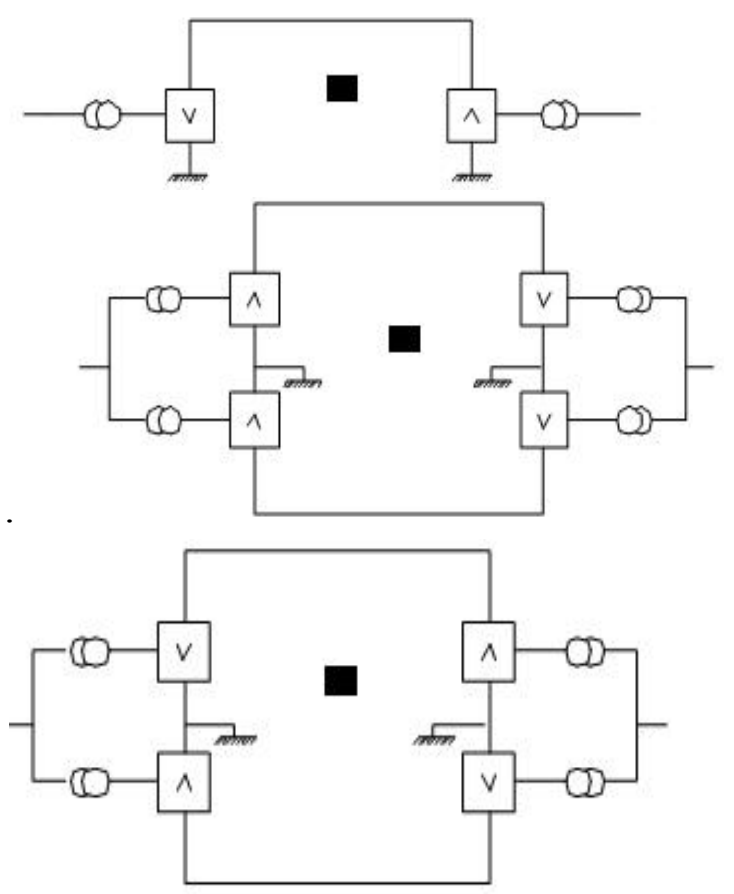

Gambar 1. Jenis-jenis saluran tegangan tinggi arus searah (a) Monopolar (b) Bipolar Homopolar

Saluran transmisi tegangan tinggi arus searah dibagi-bagi menjadi [3]:

a. saluran monopolar

b saluran bipolar dan

c saluran homopolar

Berdasarkan yang terlihat pada pada Gambar 1. hanya terdapat satu buah konduktor pada sitem transmisi monopolar (gambar 1a). Sedangkan saluran balik arusnya menggunakan bumi. Biasanya saluran transmisi dioperasikan dengan kutub negatif karena dapat mengurangi rugi-rugi korona. Sistem bipolar memiliki dua buah saluran, satu sebagai polaritas positif dan satu sebagai polaritas negatif. Terdapat dua konverter pada setiap gardu dengan tegangan yang identik dan terhubung secara seri (gambar 1b). Titik tengah dapat dihubungkan dengan tanah pada salah satu atau pada kedua ujungnya. Masing-masing saluran dapat beroperasi secara sendiri-sendiri. Karena memang dua salurantersebut tidak berhubungan. Sistem homopolar memiliki dua saluran atau lebih yang keduanya memiliki poaritas yang sama. Satu berfungsi sebagai pengirim daya dan saluran satunya sebagai saluran baliknya.

Penggunaan bumi sebagai saluran balik mempunyai beberapa keuntungan yaitu [3]:

1. Pada awalnya, saluran tegangan tinggi arus searah dapat dibangun secara homopolar dengan mempertimbangkan nilai keekonomisan. Namun, saat kebutuhan pada sisi beban meningkat, maka untuk meningkatkan keandalan dan mengurangi rugi-rugi saluran, saluran kedua dapat dibangun sehingga 
sistem transmisi menjasi sistem bipolar.

2. Dengan menggunakan sistem transmisi bipolar dengan diberi pembumian pada masing-masing sisinya, maka keandalan sisitem akan menjadi lebih tinggi. Karena bila terjadi gangguan pada salah satu saluran dan saluran tersebut terputus, maka bumi dapat berfungsi sebagai saluran balik sehingga keandalan penyaluran daya listrik dapat terjamin.

Akan tetapi selain mempunyai keuntungan seperti yang telah dijelaskan di atas, ada beberpa kerugia bila kita menggunakan bumi sebagai saluran balik. Kerugian-kerugian itu antara lain adalah [3] :

1. Aliran arus melewati bumi mengakibatkan timbulnya korosi elektrolitik pada benda-benda logam yang tertanam seperti pipa dan lain sebagainya.

2. Tidak semua tempat di muka bumi dapat difungsikan sebagai saluran balik. hal itu karena jenis dan struktur tanah di masing-masing tempet berbeda-beda. Hal itu akan mempengaruhi tegangan jatuh di titik tersebut. Dan bila menggunakan elektroda pentanahan yang cukup bagus, maka harga dan pemeliharaannya juga cukup mahal.

3. Arus yang mengalir melalui bumi dapat menyebabkan terjadinya tegangan langkah (step voltage) dan tegangan sentuh (touch voltage) yang berbahaya

4. Arus yang mengalir melalui bumi dapat mengganggu beroperasinya peralatan lain seperti kompas kapal dan sinyal perkeretaapian

\section{Konverter 12 Pulsa Kontrol Penuh}

Telah kita ketahui bahwa penyearah dioda akan menghasilkan tegangan keluaran yang tetap. Jika diinginkan suatu keluaran tegangan searah yang terkendali, maka thyristor lebih tepat digunakan dibanding dioda. Tegangan keluaran penyearah thyristor bervariasi bergantung pada sudut penyalaan pada thyristor .

Pada sistem penyearah 16 pulasa, hasil keluaran penyearah masih penuh ripple [4]. Sehingga diperlukan nilai kapasitor yang besar untuk memperhalus keluaran yang diinginkan. Penambahan kapasitor tersebut membuat sistem kontrol lebih rumit dan biaya menjadi lebih mahal. Dalam penelitian ini, untuk mengurangi penggunaan kapasitor dalam daya besar, maka digunakan sistem penyearah 12 pulsa. Sistem penyearah 12 pulsa dapat dilihat pada Gambar 2 dibawah ini.

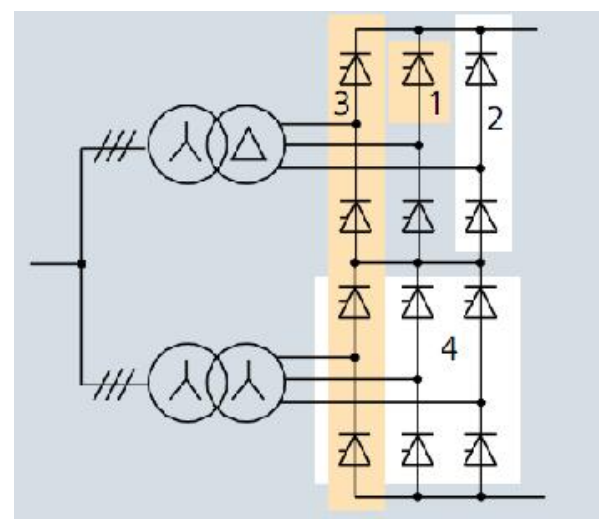

Gambar.2.Rangkaian jembatan

penyearah 6 pulsa terhubung seri membentuk penyearah 12 pulsa

Pada sistem penyearah 12 pulsa tegangan AC yang dihasilkan lebih rapat dari pada rectifier 6 pulsa karena tegangan line output dari transformator Wye dan transformator Delta mempunyai persamaan sebagai berikut: 


$$
\begin{aligned}
V_{D A}= & V_{M} \operatorname{Sin} \omega t \\
V_{D B}= & V_{M} \operatorname{Sin}(\omega t-120) \\
V_{D C}= & V_{M} \operatorname{Sin}(\omega t+120) \\
V_{Y A}= & V_{M} \operatorname{Sin}(\omega t+30) \\
V_{Y B}= & V_{M} \operatorname{Sin}(\omega t+150) \\
& V_{Y C}=V_{M} \operatorname{Sin}(\omega t-90)
\end{aligned}
$$

Bila digambarkan dalam simulasi, tegangan output yang dihasilkan akan seperti pada Gambar 3 berikut :

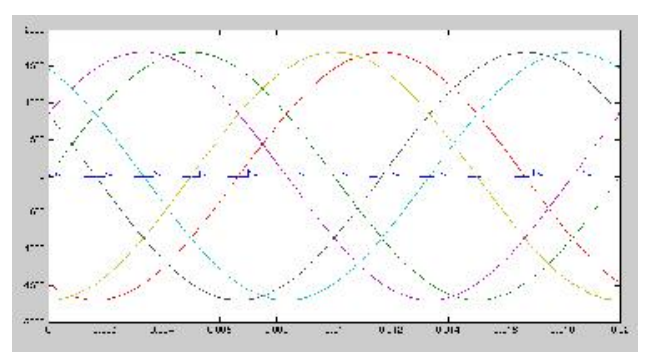

Gambar.3. Sinyal tegangan pada Output transformator Wye dan Delta

Pada Gambar 3 di atas dapat kita lihat bahwa gelombang AC yang terbangkit menjadi lebih rapat dan saling susul menyusul.

Setelah melalui thyrstor, maka akan dihasilkan tegangan DC dengan nilai seperti yang dirumuskan sebagai berikut :

$$
\begin{aligned}
V_{\mathrm{dc}} & =\frac{3}{\pi} \int_{\alpha+(\pi / 3)}^{\alpha+(2 \pi / 3)} v_{0}(\omega t) d(\omega t)=\frac{3}{\pi} \int_{\alpha+(\pi / 3)}^{\alpha+(2 \pi / 3)} v_{a b}(\omega t) d(\omega t) \\
& =\frac{3}{\pi} \int_{\alpha+(\pi / 3)}^{\alpha+(2 \pi / 3)} V_{M} \sin (\omega t) d(\omega t)=\frac{3 V_{M}}{\pi} \cos \alpha
\end{aligned}
$$

Atau untuk lebih sederhananya, rumus penyearah 12 pulsa merupakan kelipatan dua dari rumus penyearah 6 pulsa. Sehingga tegangan output pada penyearah 12 pulsa adalah 2 kali dari penyearah 6 pulsa.

\section{Model Sistem}

Thyristor yang dipakai sebanyak jumlah saluran yang terdapat pada sistem penyearah 12 pulsa, yaitu sebanyak 12 buah. Desain simulasi rectifier 12 pulsa yang dilakukan untuk lebih jelasnya dapat dilihat pada Gambar 4. berikut ini :

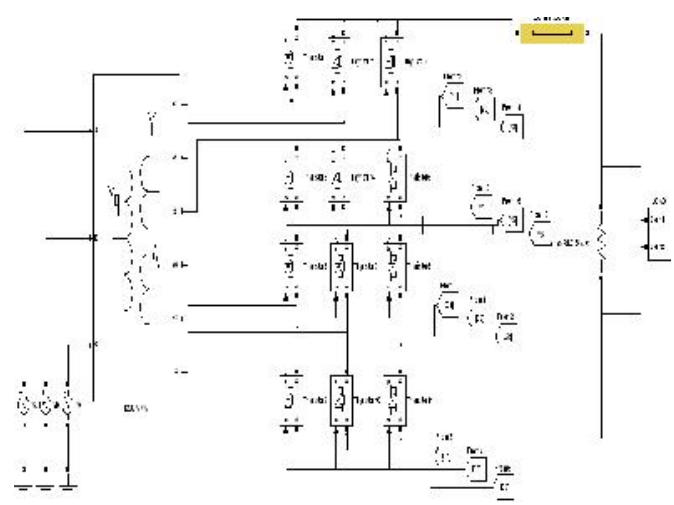

Gambar.4. Rangkaian simulasi jembatan penyearah 6 pulsa terhubung seri membentuk penyearah 12 pulsa

Sedangkan untuk sistem sudut penyalaannya, dibuat dengan menggunakan sinyal segitiga, atau lebih tepatnya berbentuk sinyal gergaji. Sinyal gergaji yang dibuat harus sesuai dengan sudut fasa dari tegangan yang akan diatur sudut penyalaannya. Sehingga awal mula munculnya sinyal gergaji bersamaan dengan mulai nya sinyal tegangan yang akan diatur. Rangkaian sinyal gergaji pada penelitian ini adalah seperti yang ditunjukkan Gambar 5 berikut ini: 


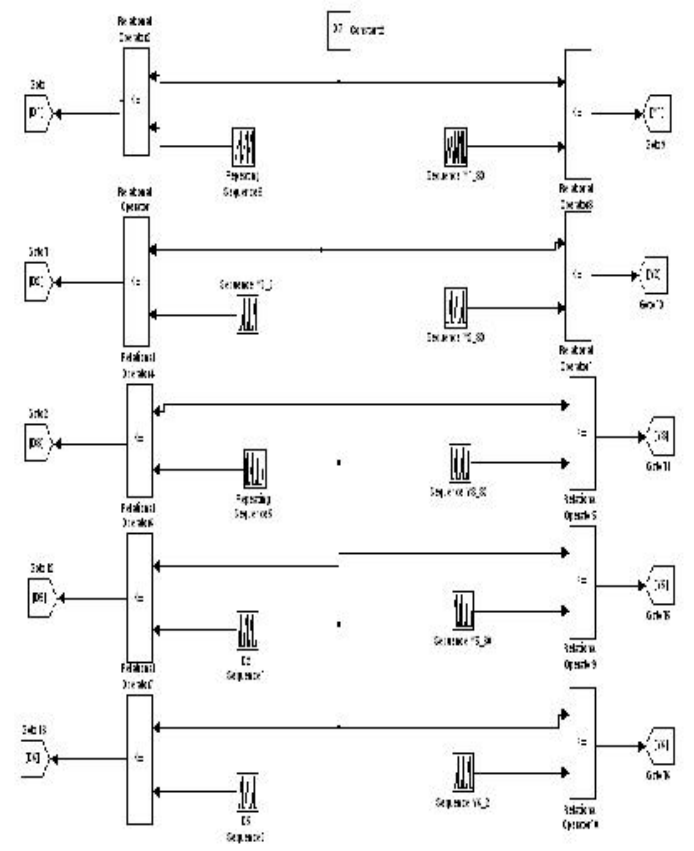

Gambar.5. Rangkaian simulasi controller sudut penyalaan

Sistem HVDC yang digunakan pada simulasi ini merupakan rangkain virtual yang tidak ada di sistem nyata. Akan tetapi, sistem yang digunakan pada simulasi ini dibuat semirip mungkin dengan sistem yang ada di kenyataan, dengan segala kelebihan dan kekurangannya. Sistem HVDC yang dibahas disini mempunyai spesifikasi sebagai berikut :

Tabel 1. Spesifikasi Sistem Transmisi

\begin{tabular}{|l|l|l|}
\hline Transformator & Vinput & $70 \mathrm{KV}$ \\
\hline & $\mathrm{V}_{\text {output Delta }}$ & $200 \mathrm{KV}$ \\
\hline & $\mathrm{V}_{\text {output Wye }}$ & $200 \mathrm{KV}$ \\
\hline & Daya & $\begin{array}{l}5000 \\
\text { MVA }\end{array}$ \\
\hline & & 0.025 \\
\hline $\mathrm{R}_{\text {line }}$ & $\mathrm{R} / \mathrm{km}$ & $500 \mathrm{KM}$ \\
\hline & $\mathrm{L}$ & \\
\hline & & 2400 \\
\hline $\begin{array}{l}\text { Beban } \\
\text { Ekivalen }\end{array}$ & Daya & MVA \\
\hline
\end{tabular}

Berdasarkan parameter sistem yang digunakan di atas, kita dapat menghitung tegangan DC maksimal yang akan kita dapatkan bila kita menyearahkan sistem AC tersebut. Besar tegangan DC yang dihasilkan adalah sebagai berikut:

$$
V_{d c \max }=2 x \frac{3 x \sqrt{2}}{\pi} 200 \mathrm{KV}=540 \mathrm{KV}
$$

\section{Fuzzy Logic Controller}

Fuzzy logic controller (FLC) merupakan teknik pengontrolan berdasarkan dasar pengetahuan manusia untuk menyetting proses kontrol. Segala sesuatu yang perlu dipertimbangkan dalam mendesain penggunaan sistem control FLC adalah respon input dan output sesuai kenyataan (himpunan crisp), faktor skala dari variabel input dan output, fungsi keanggotaan (membership function) untuk variabel input dan output, dan aturan fuzzy yang digunakan. Sistem tertutup dengan FLC dapat dilihat pada Gambar 6. berikut ini:

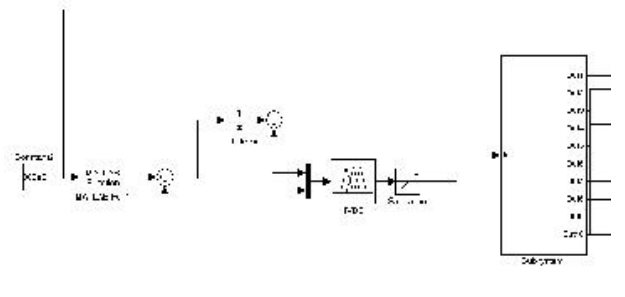

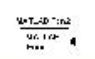

Gambar 6. Sistem kontrol FLC pada sistem penyearah 12 pulsa

Himpunan crisp untuk error input dan perubahan error diperoleh dari nilai referensi, keluaran sistem plant dan error sebelumnya. Dua masukan input, yaitu error input dan perubahan error akan diproses oleh fuzzy controller.

FLC akan mengevaluasi masingmasing input dalam bentuk error input dan 
perubahan error melalui tiga langkah proses fuzzy, yaitu Fuzzifikasi, evaluasi aturan dan defuzzifikasi.

\section{Fuzzifikasi}

Fuzzifikasi adalah proses pemetaan input crisp menjadi sekumpulan fuzzy dalam bentuk fungsi keanggotaan. Contohnya seperti yang digunakan dalam sistem ini adalah seperti yang ditunjukkan pada Gambar 7 dan 8 berikut ini:

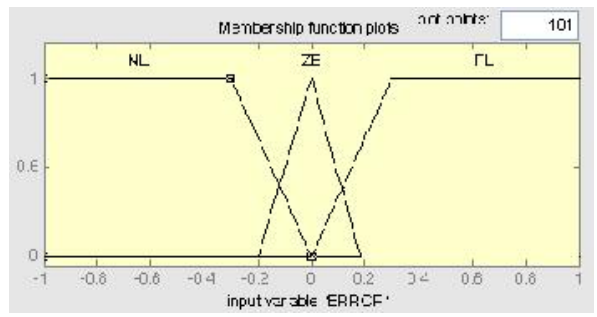

Gambar 7. fungsi keanggotaan untuk input error

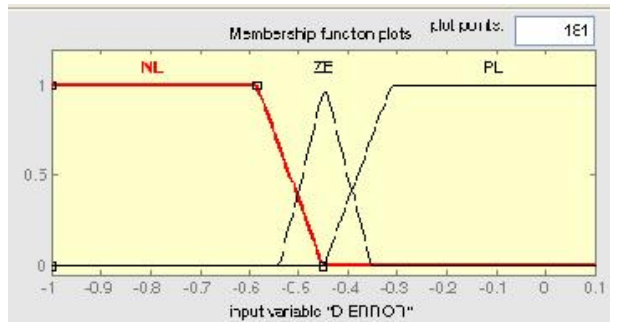

Gambar 8. fungsi keanggotaan untuk perubahan error

\section{Fuzzifikasi}

Evaluasi aturan adalah proses evaluasi derajat keanggotaan dari masingmasing sekumpulan fungsi keanggotaan inputan fuzzy berdasarkan aturan yang telah dibuat sebelumnya. Tujuan dari pembuatan aturan ini adalah untuk menentukan derajat keanggotaan dari outputan fuzzy. Aturan yang digunakan dalam sistem HVDC pada penelitian ini adalah sebagai berikut:
a.If (ERROR in NL) and (D-ERROR) is NL) then (OUTPUT is NL) (1)

b.If (ERROR in NL) and (D-ERROR) is ZE) then (OUTPUT is NL) (1)

c.If (ERROR in NL) and (D-ERROR) is PL) then (OUTPUT is ZE) (1)

d.If (ERROR in ZE) and (D-ERROR) is NL) then (OUTPUT is NL) (1)

e.If (ERROR in ZE) and (D-ERROR) is ZE) then (OUTPUT is ZE) (1)

f. If (ERROR in PL) and (D-ERROR) is NL) then (OUTPUT is ZE) (1) g.If (ERROR in PL) and (D-ERROR) is $\mathrm{ZE})$ then (OUTPUT is $\mathrm{mf} 3$ ) (1)

h.If (ERROR in PL) and (D-ERROR) is $\mathrm{PL}$ ) then (OUTPUT is $\mathrm{mf3})(1)$

\section{Defuzzifikasi}

Langkah terakhir dalam proses FLC ini adalah defuzzifikasi. Ini adalah langkah yang berkebalikan dengan proses fuzzifikasi, yaitu merubah output fuzzy menjadi fungsi keanggotaan himpunan crisp, seperti yang ditunjukkan Gambar 9 sebagai berikut.

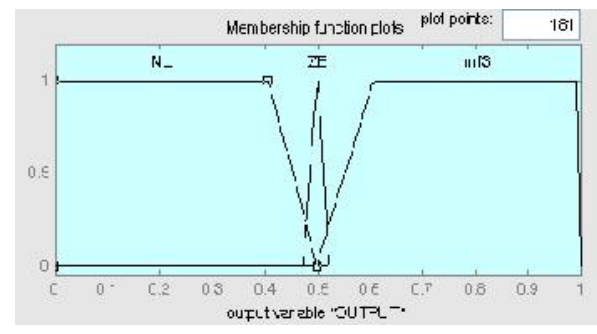

Gambar 9. Fungsi keanggotaan variabel output fuzzy

\section{Kontroller Proposional-Integral (Pi)}

Kontroller PI menghitung nilai error sebagai perbedaan antara variabel proses yang diukur dengan nilai yang diinginkan. Kontroller berusaha untuk memperkecil error yang terjadi dengan mengontrol proses input. 
Perhitungan (algoritma) kontroller PI merupakan dua jenis kontroller yang berbeda. Namun, karena sering dipakai bersamaan dalam sistem, maka sering disebut bersamaan yaitu kontroller proporsional integral atau disingkat dengan kontroller PI. Makna dari kontroller ini dapat diwakili oleh penjelasan sebagai berikut, yaitu $\mathrm{P}$ merupakan kontrol yang tergantung oleh nilai saat ini dan I merupakan kontrol yang tergantung oleh akumulasi nilai error sebelum-sebelumnya. Gabungan dari dua kontrol ini digunakan untuk mengatur proses melalui elemen kontrol seperti posisi dari kontrol valve, atau suplai daya untuk elemen pemanas, atau untuk sudut penyalaan. Gambar 10 berikut ini adalah diagram blok dari kontrol PI.

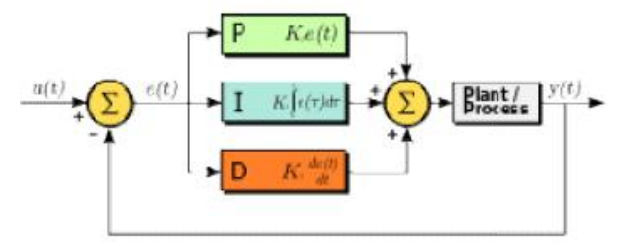

Gambar 10. Konfigurasi dari sistem Kontroller PI

Sistem HVDC dengan menngunakan kontroller PI dapat mengatur tegangan keluaran penyearah pada sisi beban sehingga bila terjadi peningkatan arus beban, dan mengakibatkan terjadinya tegangan jatuh pada saluran transmisi, sudut penyalaan thyristor diatur untuk memperoleh tegangan terminal padda sisi beban yang konstan/ yang sesuai keinginan. Sehingga kontroller pada sistem simulasi inni digunakan untuk mengatur sudut penyalaan dari thyristor ini.

Di dalam sistem ini, terjadi perubahan beban pada sisi konsumen pada detik ke $0.1,0.15,0.2,0.25$ dan 0.3 .
Tegangan yang diinginakan adalah 300 $\mathrm{kV}$. Hasil perubahan beban akan membuat tegangan pada sisi konsumen menurun menjadi kurang dari $300 \mathrm{kV}$. Hasilnya seperti gambar 11. di bawah ini.

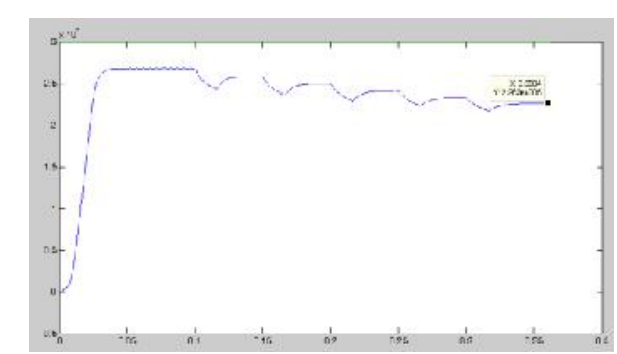

Gambar 11. Hasil simulasi loop terbuka (tanpa kontrol)

Agar tegangan pada sisi beban tetap stabil pada nilai $300 \mathrm{kV}$ maka kita akan menggunakan kontroller PI untuk menyetel sudut penyalaan. Caranya adalah sebagai berikut ini.

$\mathrm{Y}_{\mathrm{ss}}=300000$

$X_{\mathrm{ss}}=226300$

Error Steady State: $K=\frac{Y s s}{X s S}=\frac{226300}{300000}=$ 0.7543

$\mathrm{Y}(\tau)=0.632 \times \mathrm{X}_{\mathrm{ss}}=0.632 \times 226300=$ 143021

$\tau=0.0187$

$\operatorname{ts}^{*}(5 \%)=3 \times \tau^{*}=0.03$, maka $\tau^{*}=0.01$

$\mathrm{Kp}=\frac{\tau}{K . \tau *}=\frac{0.0187}{0.7543 \times 0.01}=2.479$

Persamaan transfer function dari rangkaian controller PI adalah sebagai berikut:

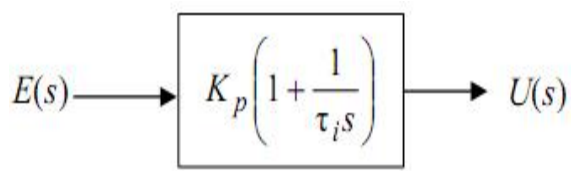

Sedangkan Rangkaian controller pada simulasi dapat dilihat pada gambar 12 berikut: 


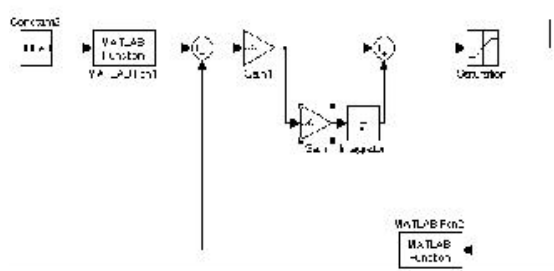

Gambar.12. Rangkaian simulasi controller PI untuk mengatur sudut penyalaan

\section{HASIL DAN DISKUSI}

Perubahan beban pada sisi konsumen akan mengakibatkan tegangan jatuh pada saluran transmisi. Pada sistem simulasi ini, kasus studi dari perubahan beban terjadi pada detik ke-0.1 , 0.15, $0.2,0.25$ dan 0.3. Arus beban maksimum adalah 8000 A pada detik ke 0.3. Perubahan arus beban pada sisi konsumen dapat terlihat pada Gambar 13 di bawah ini:

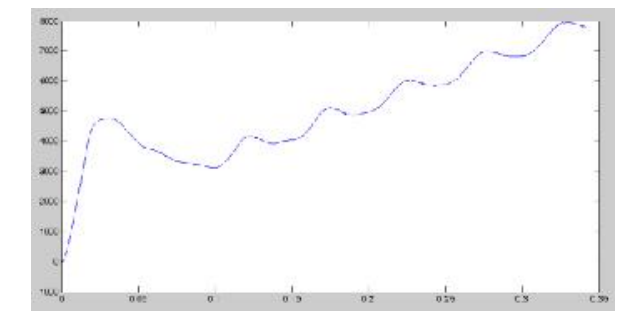

Gambar 13. Hasil simulasi arus beban

\section{Fuzzy logic controller (kontroller fuzzy)}

Agar peningkatan arus beban seperti yang terlihat pada gambar 14 di atas tidak mempengaruhi tegangan keluaran pada sisi konsumen sehingga penurunan tegangan pada sisi konsumen seperti yang terlihat pada Gambar 12 dapat terkompensasi maka diperlukan kntroller untuk mengatur sudut penyalaan dari thyristor ini.

Hasil simulasi dari penggunaan kontroller fuzzy akan mengakibatkan over shoot pada saat pertama kali beroperasi mencapai $370 \mathrm{kV}$. Terpaut selisih $70 \mathrm{kV}$ dibandingkan dengan tegangan yang diinginkan, yaitu $300 \mathrm{kV}$. Osilasi terjadi saat kontroller fuzzy beroperasi untuk menyetabilkan tegangan output pada sisi konsumen. Proses penyetabilan tegangan dengan menggunakan kontroller fuzzy dapat dilihat pada Gambar 14. di bawah ini:

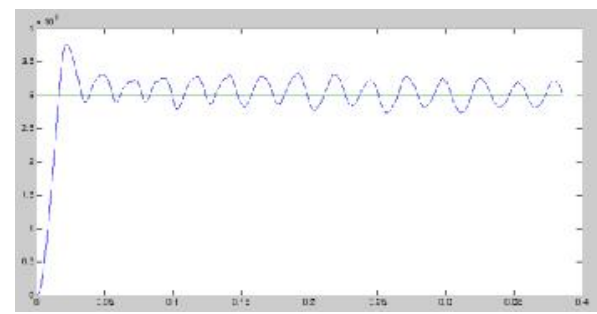

Gambar 14. Hasil simulasi pengontrolan tegangan menggunakan kontroller fuzzy

Jika kita mengabaikan batasan sistem seperti misalnya batas maksimum dari kapasitas transformator, dan tiba-tiba terjadi perubahan beban sehingga arus beban meningkat menjadi $14000 \mathrm{~A}$, pada detik 0.3, tegangan jatuh akan mencapai pada level nilai $208 \mathrm{kV}$. Kontrol dengan menggunakan fuzzy ini ternyata masih dapat menyetabilkan tegangan kembali ke nilai yang diinginkan, yaitu $300 \mathrm{kV}$ setelah 0.05 detik perubahan beban. Untuk lebih jelasnya, hasil dari simulasi ini dapat kita lihat pada Gambar 15 di bawah ini:

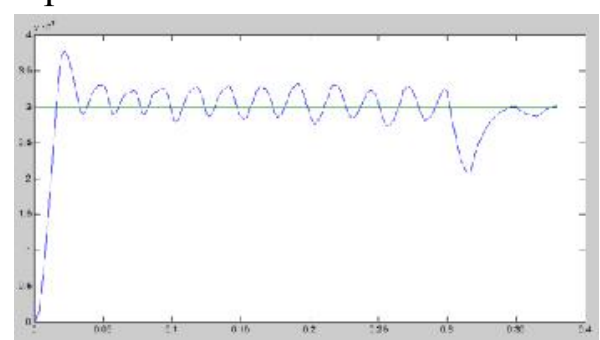

Gambar 15. Hasil simulasi kontrol tegangan menggunakan fuzzy saat terjadi kelebihan beban.

\section{Kontroller Proposional-Integral (PI)}

Kasus studi yang sama diterapkan untuk menguji kehandalan dari kontroller PI ini. Perubahan beban terjadi pada waktu 
yang sama. Hasil dari kontroller PI ini dapat terlihat pada Gambar 17 di bawah ini.

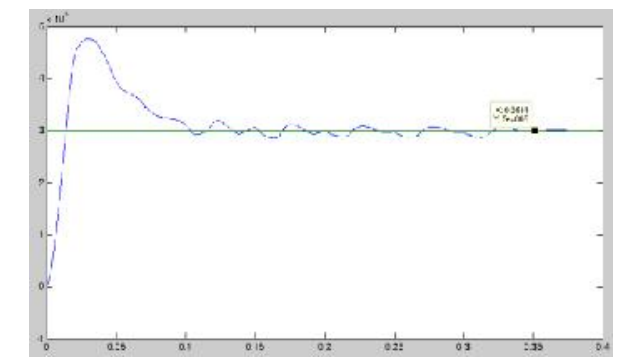

Gambar 16. Hasil simulasi kontrol tegangan menggunakan kontroller PI

Dari Gambar 16 di atas dapat kita lihat, bahwa setiap kali ada perubahan tegangan pada detik ke-0.1, 0.15, 0.2 , 0.25 dan 0.3 , tegangan akan turun sebentar, lalu kontroller PI akan mengatur agar tegangan pada sisi beban tetap konstan pada nilai tegangan $300.000 \mathrm{KV}$. Osilasi yang terjadi dengan menggunakan kontroller ini jauh lehih halus bila dibandingka dengan menggunakan kontoller fuzzy seperti yang terlihat pada Gambar 15 sebelumnya.

Namun, kelemahan penggunaan kontroller PI pada simulasi ini adalah nilai tegangan overshot pada awal beroperasinya sistem mencapai 480.000 $\mathrm{kV}$ selama 0.9 detik. Nilai overshoot ini termasuk sangat tinggi dan terjadinya juga dalam waktu yang cukup lama sebelum sistem kembali normal pada tegangan 300 $\mathrm{kV}$. Hal ini perlu menjadi pertimbangan dalam penggunaan kontroller PI bila benar-benar diterapkan pada sistem yang nyata.

Jika kita mengabaikan batasan sistem seperti misalnya batas maksimum dari kapasitas transformator, dan tiba-tiba terjadi perubahan beban sehingga arus beban meningkat menjadi $19000 \mathrm{~A}$, pada detik ke-0.3, tegangan jatuh akan mencapai pada level nilai $180 \mathrm{kV}$. Sitem dengan menggunakan kontroller fuzzy ini ternyata masih dapat menyetabilkan tegangan kembali ke nilai yang diinginkan, yaitu $300 \mathrm{kV}$ setelah 0.09 detik perubahan beban. Pemilihan nilai peningkatan beban mencapai 19000 A ini adalah beban maksimum yang dapat dikontrol dengan menggunakan kontroller PI. Nilai arus beban ini lebih besar dibandingkan nilai arus beban maskimum yang masih dapat dikontrol fuzzy, yaitu sebesar 14000 A. Untuk lebih jelasnya, hasil dari simulasi ini dapat kita lihat pada Gambar 17 di bawah ini:

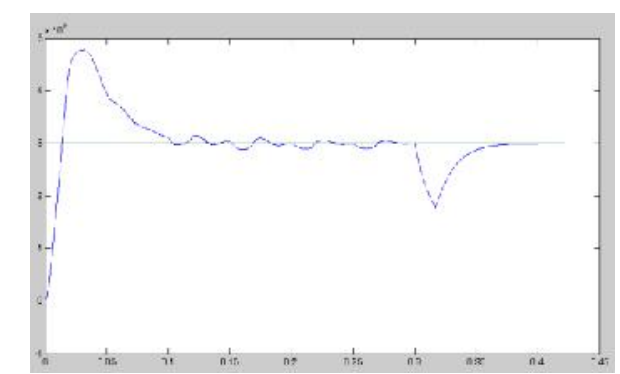

Gambar 17. Hasil simulasi kontrol tegangan menggunakan kontroller PI pada kondisi overload

\section{KESIMPULAN}

Dari hasil simulasi pada sistem HVDC $300 \mathrm{kV}$ di atas dengan menggunakan kontroller Fuzzy dan kontroller PI, kita dapat membuat beberapa kesimpulan sebagai berikut.

- Kontroller fuzzy mempunyai overshoot pada saat permulaan sistem yang jauh lebih kecil jika dibandingkan dengan menggunakan kontroller PI dan mempunyai waktu respon yang lebih cepat untuk menuju nilai yang diharapkan, yaitu300 kV.

- Kontroller PI mempunyai respon yang lebih halus dan lebih tepat 
dibandingkan dengan sistem fuzzy saat terjadi perubahan beban.

- Kontroller PI juga lebih ampuh dibandingkan dengan kontoller fuzzy. Kontroller PI tetap dapat mengontrol tegangan sistem walau terjadi kenaikan beban mencapi 19000 A dibandingkan dengan kontroller fuzzy yang hanya mampu mengontrol tegangan dengan arus beban maksimal $14000 \mathrm{~A}$.

Pada sistem ini, kontroller PI terlihat lebih ampuh dan lebih halus dalam mengontrol tegangan sisi konsumen dibandingkan dengan kontroller fuzzy. Akan tetapi, setiap sistem mempunyai larakteristik yang berbeda-beda. Sehingga bila kontroller fuzzy dan kontroller PI ini diterapkan pada sistem yang berbeda, hasil yang dicapai akan berbeda pula.

\section{DAFTAR PUSTAKA}

[1] R. Rudervall, J. Charpentier, and R. Sharma, "High voltage direct current (HVDC) transmision systems technology review paper," in Energy Week, Washington, D.C, USA, Mar. 2000.

[2] D. F.Menzies, J. Graham, and F. U. Ribeiro, "Garabi the Argentina Brazil 1000MW interconnection commissioning and early operating experience," in ERLAC Conference, Foz do Iguacu, Brazil, May-June 2001.

[3] Winardi, Bambang Sistem Transmisi Daya Searah (HVDC). Jurusan Teknik Elektro, F.T., Universitas Diponegoro, Transmisi, Vol. 0, No. 1, Juni $2005: 22-25$

[4] Ashari, M., Islam,S., and Matair,S.S., Harmonic reduction Due to Mixing
Single Phase and Three Phase Load Current Under Non-Ideal Supply Condition, http://www.upsci.com/pdf/2000harmonic-reduction.pdf. 